\title{
Older persons and malaria treatment in Nigeria
}

\author{
Olufunke A. Fayehun and Kabiru K. Salami ${ }^{1}$ \\ Department of Sociology, Faculty of the Social Sciences, \\ University of Ibadan, Nigeria
}

\begin{abstract}
This study examined the prevalence and pattern of health-seeking behavior of older people on malaria fever among the elderly in Nigeria. Data from the Nigeria Malaria Indicator Survey were used with a weighted sample of 1819 older persons aged 60 and above across the six geopolitical regions in Nigeria. The odds of fever as well as treatment seeking were predicted using logistic regression models. The prevalence rate of fever among the aged in Nigeria is $28 \%$. About half of the respondents did not receive treatment in a standard health facility. There is high patronage of chemist/patient medicine vendor/shops for malaria fever treatment among older people in Nigeria. Findings suggest that older people may use healthcare facility if it is affordable. The lifelong approach that can reduce poverty and illiteracy is recommended since the ruralurban differences in treatment seeking reduced with the inclusion of other socio-demographic variables in the model.
\end{abstract}

Keywords: Aging, malaria, fever, health-seeking, regional variation, Nigeria

\section{Résumé}

Cette étude examine la prévalence et les tendances de la demande de soins des personnes âgées sur la fièvre du paludisme chez les personnes âgées au Nigeria. Les données de l'Enquête sur les indicateurs du paludisme au Nigeria ont été utilisés avec un échantillon pondéré de I 819 personnes âgées de 60 ans et plus dans les six régions géopolitiques au Nigeria. Les chances de fièvre ainsi que la recherche de traitement ont été prédits en utilisant des modèles de régression logistique. Le taux de prévalence de la fièvre chez les personnes âgées au Nigeria est de $28 \%$. Environ la moitié des répondants n'ont pas reçu de traitement dans un établissement de santé standard. II est haut patronage du chimiste / patient, la médecine vendeur / magasins pour le traitement de la fièvre de paludisme chez les personnes âgées au Nigeria. Les résultats suggèrent que les personnes âgées peuvent utiliser des installations de soins de santé si elle est abordable. La démarche permanente qui permet de réduire la pauvreté et l'analphabétisme est recommandé car les différences rurales-urbaines dans la recherche de traitement réduits avec l'inclusion d'autres variables sociodémographiques dans le modèle.

Mots clés: vieillissement, le paludisme, la fièvre, de recours aux soins, la variation régionale, Nigeria

\section{Introduction}

Malaria, a life-threatening parasitic disease transmitted by the female Anopheles mosquitoes, causes over $\mathbf{2 0 0}$ million cases of illness each year, creating tremendous burdens of morbidity and mortality in areas of the world where it is endemic (New York Academy of Science, 20I3). According to WHO (2010) statistics, malaria caused an estimated 660,000 deaths with $95 \%$ of these occurring in Africa. It is a major cause of death for about 40 per cent of the world's population that live in the poorest countries (WHO, 2000). A study of written narratives of a large, nationally representative, sample of all deaths (Dhingra, Jha, Sharma, Cohen, Jotkar, Rodriguez, Bassani, Suraweera, Laxminarayan, and Peto, 20I0) suggests that malaria might be a cause of about 200000 deaths per year before the age of 70 years in India. This estimate includes the 120000 deaths per year at ages I5-69 years. Brown (20|2) observed that the number of people who die annually of malaria is roughly double the current estimate, with a huge overlooked death toll in older people. As malaria typically produces fever, headache, vomiting, loss of appetite and other flu-like symptoms (Akpan, 1996; Ekanem, 1996), it compromises the health and development of all age categories in the malaria-endemic regions of the world. Despite decades of significant input of resources and efforts at control, malaria is still highly endemic and has remained a major public health problem in both rural and urban communities of sub-Saharan Africa, including Nigeria (UNICEF, 2004) where the health systems are not being strengthened.

Most studies on management of malaria have often focused on pregnant women and their unborn babies as well as children under-five years of age as the most vulnerable groups. It has been reported

I. Correspondence: Kabiru K. Salami, PhD, kabsalami@yahoo.co.uk 
that 60 percent of outpatient visits and 30 percent hospitalizations attributable to malaria, an estimated 300,000 mortality due to malaria among children each year in sub-Saharan Africa, and about II per cent maternal mortality are caused by malaria (WHO, 2000; FMOH, 2008). To date, there is inadequate information about the behavior of older persons concerning management of malaria and fever, yet the elderly are vulnerable to diseases and illnesses due to their physiological state (Asiyanbola, 2008).

\section{Literature review and theoretical framework}

Several studies pertaining to the health seeking behavior of different demographic groups have been carried out in Nigeria (Salami and Brieger, 2006; Salami and Olugbayo, 2013), yet little attention is often paid to the older persons. A study (Unanka, 2002) that documents the living condition of the elderly in south-east Nigeria, ranked malaria top $(72 \%)$ on the list of illnesses common to the elderly; yet there is dearth of information on their patterns of health seeking behavior pertaining to fever and malaria.

Globally, the population of the elderly is increasing at a high rate due to improved life expectancy and decline in disability and mortality at older age (Freeman et. al., 2002; Manton and Gu, 200I). Troisi, (2004) projected that by $2025,71.9 \%$ of the world elderly population will be found in developing nations. In Nigeria, the elderly formed a significant group, with increasing rate, which may be doubled in the next decade (Ajomale, 2007). While the progression in the rate of the population of the elderly demands the attention of gerontologists, the review by Asiyanbola (2008) indicated that focused studies on the elderly in Nigeria are few. In spite of the dearth of studies on the elderly, the few existing ones are focused on issues ranging from elderly destitute (Fajemilehin, Ayandiran and Salami, 2007), the description of the traditional form of care of the elderly (Okoye, 2004) and living condition and physical well-being of the elderly in urban Nigeria (Asiyanbola, 2004). Others are life-satisfaction of the elderly (Adeokun, 1986), effects of the structural adjustment programme on the elderly (Ekpenyong, 1995), and the nutritional assessment and health status of the elderly (Bakare et al., 2004). No study has significantly documented the behaviour of the elderly not only in the management of malaria but also in a national coverage platform. There is therefore the need to document the behaviour of the elderly concerning prevention, treatment and management of malaria in Nigeria.
The same deprivation factors that often pose challenges to aging such as gender roles, norms, cultural practices, and behaviors (Asiyanbola, 2005; 2008; Kimuna, 2005; Ajomale, 2007) can strongly influence disease prevention, care seeking, and access to treatment of illnesses such as malaria. In a study of risk factors for mortality from imported malaria in the United Kingdom (Checkley, Smith, Smith, Blaze, Bradley, Chiodin and Whitty, 20I2), mortality was found to increase steadily with age, and with a case fatality of $25 / 548(4.6 \%)$ in people aged 65 and above. Those born in African countries with endemic malaria had a case fatality of $0.4 \%$ (36/ 8937) compared with $2.4 \%$ (142/5849) in others.

Although men and women of all age groups could be affected by malaria, physiological, social and chronological factors contribute to the different impact that malaria has on older persons. Dhingra, et al. (2010) also reported about I.3 million deaths from infectious diseases before age 70 in rural areas with fever as the main symptom. These data are supported by previous reports of increased case fatality (Greenberg and Lobel, 1990) and higher level of parasitaemia in elderly people (Checkley et al., 2012). Such impact facilitates vulnerability to other diseases and illnesses, which may result in elderly mortality. Onyeneho, Orji, Okeibunor and Brieger (20I3) found several demographic factors, such as older age bracket, ever attended school, currently living with a partner, ever married, and wealth, as significantly associated with compliance. Compliance was also found higher among respondents who had ever been married than among those who had never been married, and compliance was also higher among those in paid employment and those in a higher wealth quintile. A study by Dhingra et al., (2010) that attributed about $90 \%$ of deaths to malaria in India were reported in rural areas and $86 \%$ were not in any health-care facility. Death rates attributed to malaria correlated geographically in India.

Current circumstances that have helped malaria to thrive include the unhygienic situation in which many citizens live (Brieger et. al., 200I). For instance, torpid water, pervasiveness of wreckages and wild grass create breeding grounds for the mosquito vector to thrive. Unfortunately, government allocation of funds for malaria is insufficient to channel a wider coverage in the preventive and treatment measures against the spread of malaria. In spite of the substantial progress that had been made towards malaria control and, in some places, towards elimination, the gains were still fragile. The malaria situations have caused both economic and social burdens on the country (Roll Back Malaria, 2005). This study, therefore, focuses on the health 
seeking behavior of older persons in Nigeria, sources of support and treatment during malaria episodes, and factors that influence malaria management among the elderly in Nigeria.

\section{Data and method}

This study utilized a secondary based data from the 2010 Nigeria Malaria Indicator (MIS) Survey 2010. The survey is the first MIS in Nigeria that provided information on malaria indicators and prevalence for the six geopolitical regions from a nationally representative sample size of 5859 households (National Population Commission (NPC) and National Malaria Control Programme (NMCP) and ICF International 20I2). Approval to use the MIS 2010 data set was received from the MEASURE DHS, the organization in charge of the dataset. The household member dataset was analyzed to show the patterns of malaria fever health seeking behavior of the elderly in Nigeria. Since the focus of this study is on older people, household member aged 60 years and above were selected. Age 60 years was used as the cut-off point for the elderly population in consonance with the definition of the WHO (20/3); it is also the base age of retirement in the Nigerian public service. However, in recent times, debates on retirement age in Nigeria have favoured moving the age of retirement to 65 or 70 years for different professions. Household sampling weight was used to correct sampling error in the study population. This gives a weighted sample of 1819 older persons across the six geopolitical regions in Nigeria.

The main dependent variable is seeking treatment for malaria fever. Other malaria treatment related dependent variables considered include I) the experience of fever two weeks preceding the survey, 2) the place malaria treatment was sought, and 3) cost of treatment. The independent variables are sex, educational level, region, wealth index, residence and relationship structure and use of mosquito nets. The variables were re-classified for this study as follows:

\begin{tabular}{ll} 
Prevalence of fever & yes, no (response to question: last two weeks sick with fever) \\
\hline Sought for treatment & yes; no (response to question: did get any treatment for fever in last two weeks) \\
\hline Place of treatment & $\begin{array}{l}\text { Government hospital/ health centre /clinic; Mobile clinic; } \\
\text { Private hospital/health centre/clinic; Self treatment } \\
\text { Medicine Vendors (PMV); } \\
\text { Shop/drug/hawker; Traditional practitioner; }\end{array}$ \\
\hline Cost of treatment & Actual cost of treatment in Naira \\
\hline Use of mosquito nets & yes, no (response to question: type of mosquito nets person slept under last night) \\
\hline Sex & male, female \\
\hline Age & $60-69,70-79,80$ and above \\
\hline Educational level & none, primary, secondary, tertiary \\
\hline Region & North west, north east, north central, south east, south west, south south \\
\hline Residence & urban, rural \\
\hline Wealth index & poor, middle, rich
\end{tabular}

The pattern of health seeking behavior for malaria fever among older people in Nigeria was examined using descriptive statistics. Logistic regression was used to investigate the odds of seeking treatment for fever among different groups; a ratio greater than one implies that the group has higher likelihood of seeking treatment for fever than the reference category. The study is limited because of the proxy nature of reporting for fever; although, some household members were interviewed together, there were instances where the information on fever for the household members in the 2010 NMIS is from proxy reports (NPC, NMCP and ICF International, 2012).

\section{Results}

The percentage distributions of selected sociodemographic characteristics of the aged in this study are presented in Table I. The proportion of male is slightly greater than female older persons in this study. More than $70 \%$ of the current cohort of elders in Nigeria do not have any formal education, live in rural area and are below 80 years. The wealth index is a well-known indicator of the economic status of the household that is consistent with expenditure and income measures (NPC, NMCP and ICF International, 2012). The result shows that at least one third of the elders live in a poor household. 
Table I Background characteristics of the selected older people $(n=1819)$

\begin{tabular}{|c|c|c|c|}
\hline \multicolumn{2}{|c|}{ Characteristics } & Frequency & Percentage \\
\hline \multicolumn{4}{|c|}{ Sex of respondents } \\
\hline 2 & Male & 1045 & 58 \\
\hline 2 & Female & 773 & 43 \\
\hline \multicolumn{4}{|c|}{ Highest Educational level } \\
\hline 2 & No formal education & 1276 & 71 \\
\hline 2 & Primary education & 363 & 20 \\
\hline 2 & Secondary and above & 157 & 9 \\
\hline \multicolumn{4}{|c|}{ Residence } \\
\hline 2 & Urban & 477 & 26 \\
\hline 2 & Rural & 1342 & 74 \\
\hline \multicolumn{4}{|c|}{ Region } \\
\hline 2 & North Central & 54 & II \\
\hline 2 & North East & 63 & 13 \\
\hline 2 & North West & 72 & 14 \\
\hline 2 & South East & 79 & 16 \\
\hline 2 & & 54 & $\mathrm{II}$ \\
\hline 2 & $\begin{array}{l}\text { South South } \\
\text { South West }\end{array}$ & 178 & 35 \\
\hline & South Vvest & & \\
\hline \multicolumn{4}{|c|}{ Wealth index } \\
\hline 2 & Poor & 716 & 39 \\
\hline 2 & Middle & 392 & 22 \\
\hline 2 & Rich & 712 & 39 \\
\hline
\end{tabular}

Figure 1: Incidence and seeking for treatment of malaria fever among the aged in Nigeria

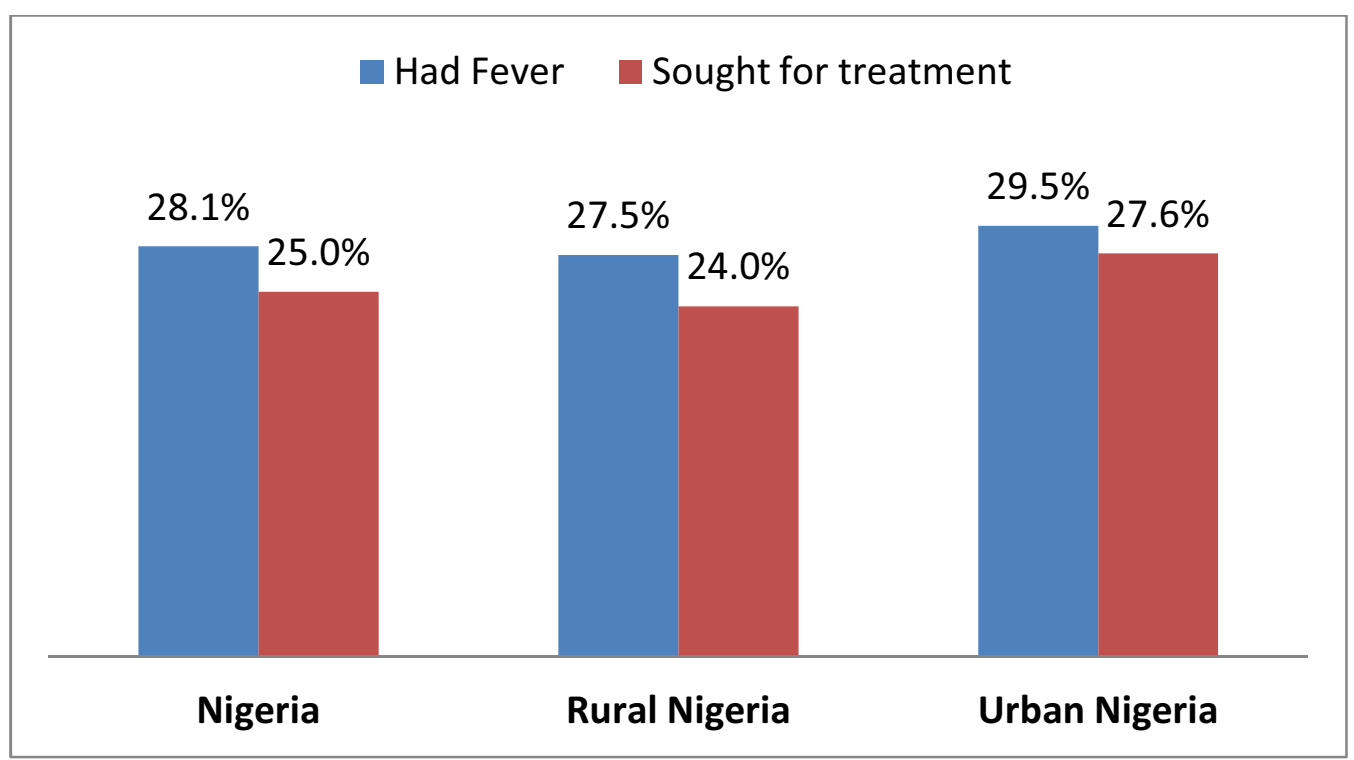




\section{Prevalence and pattern of treating malaria fever among the aged in Nigeria}

Figure I shows the prevalence of fever and health seeking behavior among the older people sixty years and above in Nigeria. At least one out of four older people experienced fever in the last two weeks preceding the survey. Although, there is no significant difference in the prevalence of fever by residence $(p>0.05,2: 0.663)$, the percentage of urban elders who experienced fever is slightly more than the rural elders. The result also shows that irrespective of the location, not all the elder who had fever sought for treatment.

Table 2 presents the prevalence and seeking of treatment for fever with selected socio-demographic characteristics of the elderly in Nigeria. With the exception of sex of respondents, all other variables were significantly associated $(p<0.05)$ with health seeking behavior of the elderly in Nigeria. Elders who live in the urban area of the southern part of Nigeria, have higher education and are rich were more likely to seek treatment than other groups. Although the south western part has the highest prevalence of malaria fever two weeks preceding the survey, majority of these elders sought for treatment. Prevalence of fever is high among female elders in Nigeria, especially in urban area where the rate for female is $35 \%$ compared to $25 \%$ for male. This pattern is also similar for treatment seeking for fever for male and female elders. The elders in Nigeria with at least secondary education have the lowest prevalence rate of fever, and are likely to seek for treatment.

Table 2 Background characteristics of the selected older people $(n=1819)$

\begin{tabular}{|c|c|c|c|c|c|c|}
\hline \multirow[t]{2}{*}{ Characteristics } & \multicolumn{2}{|l|}{ Nigeria } & \multicolumn{2}{|l|}{ Rural } & \multicolumn{2}{|l|}{ Urban } \\
\hline & Prevalence & $\begin{array}{l}\text { Sought } \\
\text { treatment }\end{array}$ & Prevalence & $\begin{array}{l}\text { Sought } \\
\text { treatment }\end{array}$ & Prevalence & $\begin{array}{l}\text { Sought } \\
\text { treatment }\end{array}$ \\
\hline \multicolumn{7}{|l|}{ Region* } \\
\hline - North Central & 15.6 & |4.| & 13.5 & 13.1 & 22.8 & 18.0 \\
\hline - North East & 29.4 & 22.4 & 27.8 & 20.5 & 34.6 & 26.9 \\
\hline - North West & 30.8 & 24.3 & 32.8 & 24.9 & 20.5 & 20.5 \\
\hline - South East & 22.6 & 20.9 & 25.8 & 23.2 & 15.0 & 15.0 \\
\hline South South & 29.2 & 26.0 & 27.7 & 23.8 & 37.9 & 37.9 \\
\hline $\begin{array}{l}\text { - South South } \\
\text { - South West }\end{array}$ & 39.3 & 37.8 & 38.6 & 36.9 & 40.5 & 39.3 \\
\hline \multicolumn{7}{|l|}{ Sex of respondents } \\
\hline - Male & 27.8 & 25.2 & 28.8 & 28.3 & 24.9 & 22.0 \\
\hline - Female & 28.6 & 25.0 & 26.0 & 23.6 & 35.0 & 29.9 \\
\hline \multicolumn{7}{|l|}{ Highest Educational level* } \\
\hline - No formal education & 26.1 & 25.7 & 25.0 & 20.9 & 30.1 & 26.8 \\
\hline - Primary education & 36.7 & 33.4 & 37.3 & 35.3 & 34.6 & 34.6 \\
\hline - Secondary and above & 24.4 & 21.5 & 29.0 & 27.6 & 20.7 & 20.7 \\
\hline \multicolumn{7}{|l|}{ Wealth index* } \\
\hline - Poor & 27.6 & 22.8 & 27.3 & 22.3 & 30.6 & 25.3 \\
\hline - Middle & 23.7 & 21.4 & 21.0 & 19.3 & 37.5 & 33.6 \\
\hline - Rich & 31.0 & 29.3 & 33.9 & 32.5 & 27.8 & 25.8 \\
\hline
\end{tabular}

* Significant at 0.05 level

The results presented in Table 3 show that the place of treatment for malaria fever differs significantly in rural and urban area of Nigeria. More than half of the elders received treatment in nearby chemist shops or patient medicine vendors. Seeking treatment from the traditional practitioners is significantly higher in rural area than urban as expected. Conversely, self-treatment is higher in urban than the rural area. 
Table 3 Pattern of health seeking behavior on fever among older people in Nigeria

\begin{tabular}{|c|c|c|c|}
\hline \multirow[t]{2}{*}{ Characteristics } & \multicolumn{3}{|c|}{ Percentage of $(n)$} \\
\hline & Nigeria & Rural & Urban \\
\hline \multicolumn{4}{|l|}{ Place of treatment } \\
\hline \multirow{2}{*}{ - Government hospital/ health centre /clinic } & 18.0 & 18.3 & 17.5 \\
\hline & 15.4 & 11.5 & 25.4 \\
\hline - Private hospital/health centre/clinic & 1.2 & 1.6 & 0.8 \\
\hline - Mobile clinic & 49.7 & 52.2 & 42.9 \\
\hline \multirow{2}{*}{ - Chemist/PMV } & 5.9 & 6.1 & 5.6 \\
\hline & 4.0 & 5.1 & 0.8 \\
\hline \multirow[t]{2}{*}{ - Shop/drug/hawker } & 5.8 & 5.1 & 7.1 \\
\hline & $(n=438)$ & $(n=3 \mid 2)$ & $(n=126)$ \\
\hline
\end{tabular}

Further descriptive analysis in Table 4 on the cost of treatment by place of treatment reveals that at least half of the elder who used either government or private health facilities paid more than N1000 for treatment of fever. This amount is relatively high for older people who face financial constraints. This explains why the overwhelming majority of them patronize Chemists, PMV, shops, drug hawkers and traditional practitioners (Table 4) where the cost of treatment was relatively lower.

Table 4 Association between the place and cost of treatment of fever

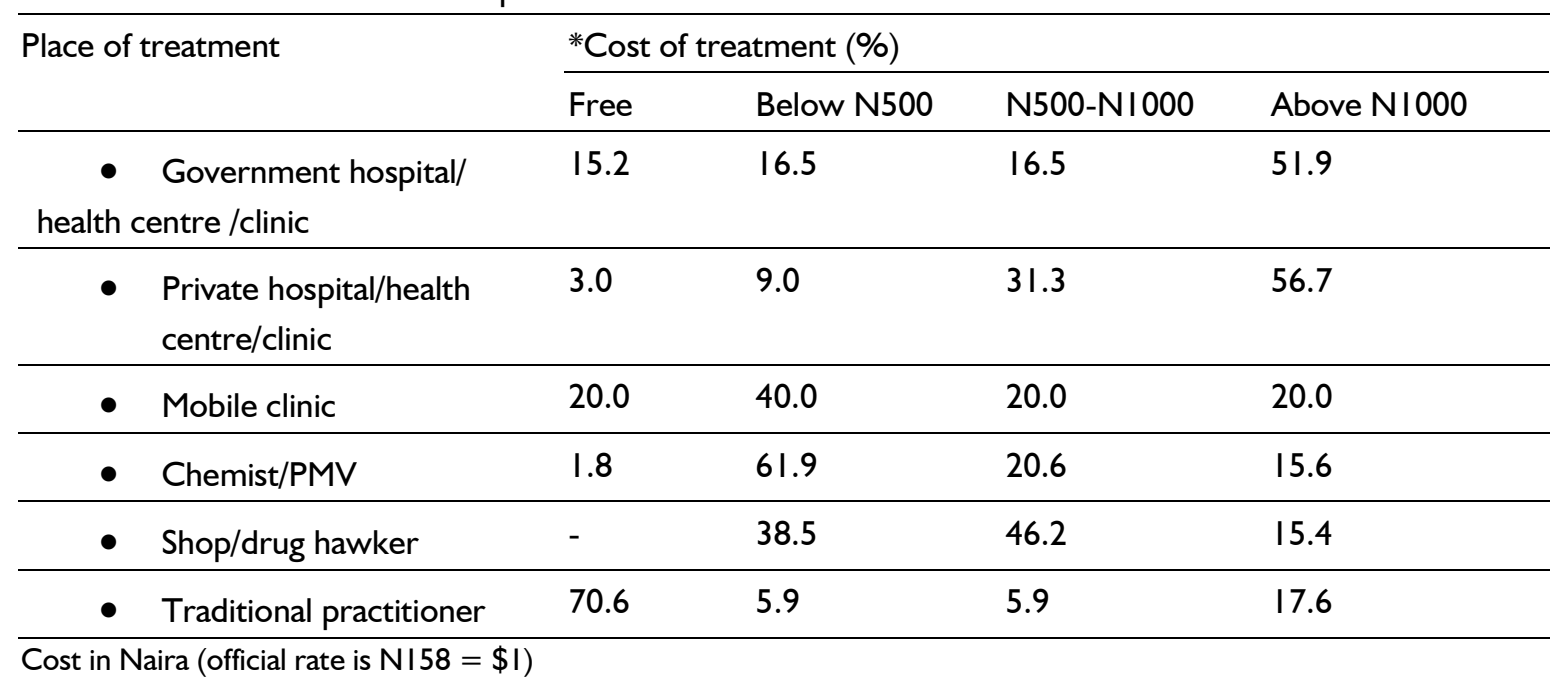

A mobile clinic is a government-owned health facility with qualified personnel usually managed at the local government level, especially in rural areas. Twenty percent reported that they were treated free while 40 percent paid below N500 for treatment. The majority of the respondent who sought treatment from the traditional practitioner received free treatment.

\section{Factors affecting health seeking behavior for fever among older people}

The odds of having fever and, seeking treatment were further estimated using logistic regression because of the dichotomy nature of the two dependent variables; a ratio greater than one implies that the group has higher likelihood of having fever or seeking treatment than the reference category. Three models were estimated for the prevalence of malaria fever among people aged 60 and above in Nigeria. Another three models were also examined for the likelihood of seeking for treatment as shown in Table 5. The first model considered the ruralurban residence; the second model included geopolitical regions of Nigeria, while the third model shows an overall effect of selected background char- 
acteristics.

Table 5 Estimated odds ratio of fever and treatment seeking on fever among the elderly

\begin{tabular}{|c|c|c|c|c|c|c|}
\hline \multirow[t]{2}{*}{ Characteristics } & \multicolumn{3}{|c|}{ Odds of Malaria Fever } & \multicolumn{3}{|c|}{ Odds of Treatment seeking } \\
\hline & Model I & Model 2 & Model 3 & Model I & Model 2 & Model 3 \\
\hline \multicolumn{7}{|l|}{ Residence } \\
\hline - Rural (ref.) & 1.00 & 1.00 & 1.00 & 1.00 & 1.00 & 1.00 \\
\hline - Urban & 1.09 & 1.01 & 0.94 & $2.12 *$ & 1.76 & 1.60 \\
\hline \multicolumn{7}{|l|}{ Region } \\
\hline - North East (ref) & & 1.00 & 1.00 & & 1.00 & 1.00 \\
\hline - North Central & & $0.44 *$ & $0.43 *$ & & $3.30 *$ & 2.88 \\
\hline - North West & & 1.05 & 1.07 & & 1.30 & 1.19 \\
\hline - South East & & 0.70 & $0.53^{*}$ & & $3.81 *$ & 3.05 \\
\hline Soutn East & & 0.99 & 0.81 & & 2.57 & 1.96 \\
\hline $\begin{array}{l}\text { - } \quad \text { South South } \\
\text { - } \quad \text { South West }\end{array}$ & & $1.54 *$ & 1.34 & & $7.68 *$ & $6.45 *$ \\
\hline \multicolumn{7}{|l|}{ Sex of respondents } \\
\hline - Female (ref.) & & & 1.00 & & & 1.00 \\
\hline - Male & & & 0.89 & & & $1.90 *$ \\
\hline \multicolumn{7}{|l|}{ Highest Educational level } \\
\hline - No formal education (ref.) & & & 1.00 & & & 1.00 \\
\hline - Primary education & & & $1.65^{*}$ & & & 1.24 \\
\hline - Secondary and above & & & 0.84 & & & 4.38 \\
\hline \multicolumn{7}{|l|}{ Wealth index } \\
\hline - Poor (ref.) & & & 1.00 & & & 1.00 \\
\hline - Middle & & & 0.80 & & & 1.14 \\
\hline - Rich & & & 1.17 & & & 1.43 \\
\hline
\end{tabular}

* Significant at 0.05 level

There is no significant difference in the odds of malaria fever by residence in all the models. The inclusion of geopolitical region in model 2 shows some difference across the country; the likelihood of the aged having malaria in the North Central is significantly lower than all the regions of the country. On the contrary in this study, the South Western region has the highest significant odds of having malaria fever. While the effect of sex and wealth index are not significant on the chances that the older people in Nigeria will have fever, educational attainment is a significant predictor in this study. Surprisingly, elders with primary education have significant higher odds of fever than other educational groups.

The result on malaria treatment seeking further shows that older people who reside in urban areas have twice the odds of seeking for treatment for fever than those in the rural area of Nigeria. There is significant regional difference in the health seeking behavior of older people in Nigeria. A remarkable finding in this study is that the elders in the South west have the highest likelihood of seeking for treatment for malaria fever than other regions. Although, older people in North Central and South East Nigeria are three times more likely to seek for treatment for fever than those in the North East, those in South West are seven times more likely to do so. This difference persists albeit with slight variation after the introduction of sex, educational level, and wealth index in the third model.

These background variables removed the significant differences observed with respect to region and residence and health seeking behavior of the older people in Nigeria. The percentage change in odds of seeking treatment for fever declined by $25 \%$ between the values in model I, where only residence was considered, to model 3 , where all the variables were included. This suggests that the differences in health seeking behavior between the regions as well as rural and urban can be significantly reduced if the background variables are relatively similar. 


\section{Discussion}

The twenty-eight percent prevalence rate for malaria fever among older people in Nigeria observed in this study is consistent with the findings from NMIS 2010 (NPC, NMCP and ICF International, 20I2). It also supports findings by lloh et al. (2012) and Unanka (2002) that acute malaria is among the three most common geriatrics emergencies in Nigeria. Apart from children, the older people aged 60 and above have the highest prevalence rate in Nigeria. The immunity level of the elderly is relatively lower than other age cohorts because of their physiological state (Asiyanbola, 2008).

Although the proportion of those who received treatment for fever is high, about one out of two did not receive treatment in a standard health facility. This is of great concern in the course of peaceful and successful aging. Older people in Nigeria are not predisposed to presenting illness in the hospital (Adebusoye et al, 20I I); they rather prefer to attend a chemist or drug store where auxiliary pharmacy assistant have little training on prescribed drugs (Oshiname and Brieger, 1992). In Nigeria, having a chemist or being a patient medicine vendor does not necessarily require higher educational attainment or training; the art of selling drugs is learnt in apprenticeship or as a trade. This has implications for the prescription of drug among other issues for ailments and sickness (Oladepo, et. al., 2007); they are likely to prescribe wrongly and sell expired drugs (Brieger, Osamor, Salami, Oladepo and Otusanya, 2004). Even in a localized study where awareness of "Artemisinin-Based Combination Therapy" was shown to be high among chemist owners, knowledge of correct timing for drug administration was low (Chukwuocha, Nwakwuo, and Mmerole, 2013). As overmedication and wrong prescription of drugs are detrimental to health of individuals generally, such practices can actually trigger severe consequences on the health of older persons

Conversely, older people's patronage of hospitals, clinics or health centres, either government or private owned, is low. This is a reflection of low accessibility and utilization of health care in Nigeria. The effect of high cost on utilization of medical treatment among the older people is clearly demonstrated in this study. The Chemist/PMVs, who are always within the neighborhood, can manage fever and malaria for older persons at a cost less than the health facility. It seems that older persons are satisfied with the treatment that they received from the Chemist/PMVs owing to intrinsic values that they derived from it which may include proximity, full attention of the attendants and low cost attracted. About seventy percent of those who received treat- ment from the traditional practitioner claimed that it was free. There is need for an ethnographic study that can detail the reasons for differences in the choice of malaria treatment sources for the elderly.

Regional differences exist in the health seeking behavior of older people in Nigeria. Older people in northern Nigeria are less likely to receive treatment for fever than those in the southern part. The study confirms that the usual north-south dichotomy on health seeking is also applicable to the older people (NPC and ORC Macro, 2009; NPC, NMCP and ICF International, 20I2). Likewise, older people who live in urban area, have higher education, and belong to the high wealth index group sought for treatment than other groups. This also is an extension of the rural-urban differentials in malaria-related healthseeking practices that had been observed among various demographic groups in Nigeria (Obikeze, et al., 20I0; Okeke and Okeibunor, 20I0; Onabanjo and Nwokocha, 20I2). The estimated odds shows that the significant differences observed for region and place of residence with respect to health seeking behavior of older people could be obliterated if there were similarity in education and wealth among the elderly.

\section{Conclusion}

Malaria fever, one of the most common geriatric illnesses, can significantly cause mortality among older people irrespective of country and culture. This study empirically documents the pattern of health seeking behavior pertaining to malaria treatment of the elderly in Nigeria using a nationally representative sample from the most recent survey (2010). Most of the older people received treatment for malaria fever; however, about half of them did not receive treatment in a standard health facility. The high patronage of chemist, patient medicine vendor and shop raises health concern because of the likelihood of overmedication and wrong prescription of drug. This study suggests that regional difference in health seeking can be avoided if there is a lifelong approach that curbs poverty and illiteracy. Accessibility and affordability of health care is also pertinent for effective use of health care facility by older people in Nigeria.

\section{Acknowledgement}

We are grateful to: ICF Macro for permission to use the Nigeria Malaria indicator survey 2010; and The National Universities Commission and The Dave Omokaro Foundation for sponsoring the Certificate in Applied Gerontology at the University of North Texas (UNT), Denton Texas, USA. We appreciate the support of Dr Ami Moore for her insightful com- 
ments on the first draft that was submitted as term paper.

\section{References}

Adebusoye LA, Ladipo MM, Owoaje ET, Ogunbode AM (20II) Morbidity pattern amongst elderly patients presenting at a primary care clinic in Nigeria. African Journal of Primary Health Care and Family Medicine 20I I;3(I), Art. \#2I I, 6 pages. doi:10.4102/phcfm.v3il.2II.http:// www.phcfm.org/index.php/phcfm/article/ viewFile/2I I/233

Adeokun LA (1986) Aging and the status of the elderly in Nigeria. Gerontol. Mar -Apr; 19(2):82-6

Ajomale $O$ (2007) Country report: Ageing in Nigeria - Current State, Social and Economic Implications. ISA RCI I ,Sociology of Aging' Summer 2007

Akpan, HEM (1996) Home management of malaria in children. Malaria Society of Nigeria Newsletter I(I): 8-9.

Asiyanbola RA (2004) "Social support/ networks, urban condition and physical well being of the elderly in Africa: a preliminary survey in Ibadan, Nigeria" A paper presented at the International Conference on "Rapid Ageing and the changing role of the elderly in African households", Organized by the Union for African Population Studies UAPS/UEPA (Senegal), the HSRC in collaboration with the Department of Social Development (South Africa) 18-20 August, 2004, Pretoria, South Africa

Asiyanbola RA (2005) Elderly family care situation, daily activities, housing and physical wellbeing in Nigeria. Paper submitted for presentation as poster at the International Union for the Scientific Study of Population (IUSSP/UIESP) XXV International Population Conference Tours, France, 18-23, 2005.

Asiyanbola RA (2008) Assessment of Family care, Housing, Gender, Daily activities, and Physical Wellbeing of the Elderly in Ibadan, Nigeria. ASSET Series C (2008) 3 (I): 63-78

Bakare OE, Ojofeitimi EO, Akinyemi A (2004) "Nutrition assessment and health status of the elderly in Southwestern, Nigeria" A paper presented at the International Conference on "Rapid Ageing and the changing role of the elderly in African households", Organized by the Union for African Population Studies UAPS/ UEPA (Senegal), the HSRC in collaboration with the Department of Social Development (South Africa) 18-20 August, 2004, Pretoria, South Africa.

Brieger WR, Sesay HR, Adesina H, Mosanya ME,
Ogunlade PB, Ayodele JO and Orisasona SA (200I) Urban malaria treatment behaviour in the context of low levels of malaria transmission in Lagos, Nigeria. African Journal of Medicine and Medical Sciences; 30, Suppl. 7-I5

Brieger WR, Osamor PE, Salami KK, Oladepo O and Otusanya SA (2004) Observations of interaction between patent medicine vendors and customers in urban and rural Nigeria. Health Policy and Planning, 19(3): 177-182.

Brown D (2012) New study doubles estimate of global malaria deaths. Health \& Science; The Washington Post.

http://www.washingtonpost.com accessed on 24/ $10 / 2013$

Checkley AN, Smith A, Smith V, Blaze M, Bradley D, Chiodin PL, and Whitty CJM (20I2) Risk factors for mortality from imported falciparum malaria in the United Kingdom over 20 years: an observational study. BMJ; 344:e21 I6 doi: I0. I I36/bmj.e2 I I6 page I- I I

Chukwuocha, UM, Nwakwuo, GC, \& Mmerole, I (20I3). Artemisinin-Based Combination Therapy: Knowledge and Perceptions of Patent Medicine Dealers in Owerri Metropolis, Imo State, Nigeria and Implications for Compliance with Current Malaria Treatment Protocol. Journal of Community Health, 38, 759-765.

Dhingra N, Jha P, Sharma VP, Cohen AA, Jotkar RM, Rodriguez PS, Bassani DG, Suraweera W, Laxminarayan R, and Peto R (20I0) Adult and child malaria mortality in India: a nationally representative mortality survey. Lancet; 376 : 1768-74

Ekanem, OJ., Weisfeld, JA, Salako, LA., Nahlen, BL. et al 1990. Sensitivity of Plasmodium falciparum to chloroquine and sulfadoxine/pyrmethamine in Nigerian children. Bulletin of the World Health Organisation 68(I): 45-62.

Ekpenyong S (1995) The structural adjustment programme and the elderly in Nigeria. Int. J. Aging Hum. Dev. 4I (4):267-80

Fajemilehin BR, Ayandiran EO and Salami KK (2007) Elderly Destitution in lle-Ife, Osun State, Nigeria. International Journal of Nursing Practice. 13 (3): $161-165$

FMOH, (2008) National Malaria and Vector Control Division. 2008. Federal Republic of Nigeria: Training manual for management of malaria in Nigeria. Abuja: Federal Ministry of Health, 6.

Greenberg AE, Lobel HO (1990) Mortality from Plasmodium falciparum malaria in travelers from the United States, 1959 - 1987. Ann Intrn Med; I 13:326-327

Iloh G, Amadi AN, Awa-Madu J. (20I2) Common geriatric emergencies in a rural hospital in South- 
Eastern Nigeria. Niger J Clin Pract I5: 333-7

Kimuna SR (2005) Living Arrangement and Conditions of Older People in Zimbabwe. African Population Studies Vol. 20, No.2: 143-163.

Manton KG, Gu X (200I) "Cganges in the prevalence of chronic disability in the United States black and nonblack population above age 65 from 1982 to 1999", Proceedings of the National Academy of Sciences, 98(I I), 6254 6359.

National Population Commission (NPC) (Nigeria) and ORC Macro (2009) Demographic and Health Survey, 2008, Calverton, Maryland: National Population Commission and ORC Macro.

National Population Commission (NPC) [Nigeria], National Malaria Control Programme (NMCP) [Nigeria], and ICF International (20I2) Nigeria Malaria Indicator Survey 2010. Abuja, Nigeria: NPC, NMCP, and ICF International.

New York Academy of Sciences (2013) Advances in Plasmodium Vivax Malaria Research. http:// www.nyas.org/publication. Accessed 25/8/20I3.

Obikeze, E, Okoronkwo, I, Onwujekwe, O, Onwujekwe, OC, and Uzochukwu, B. (20I0). Improving Quality of Malaria Treatment Services: Assessing Inequities in Consumers' Perceptions and Providers' Behaviour in Nigeria. International Journal for Equity in Health, 9(22).

Okeke, TA, and Okeibunor, JC (2010). Rural-Urban Differences in Health-Seeking for the Treatment of Childhood Malaria in South-East Nigeria. Health Policy, 95(I), 62-68.

Okoye UO (2004) "The erosion of traditional forms of care for the elderly and its implication for the elderly in Nigeria" A paper presented at the International Conference on "Rapid Ageing and the changing role of the elderly in African households", Organized by the Union for African Population Studies UAPS/UEPA (Senegal), the HSRC in collaboration with the Department of Social Development (South Africa) 18-20 August, 2004, Pretoria, South Africa.

Oladepo O, Salami KK, Adeoye BW, Oshiname F, Ofi B, Oladepo M, Ogungbemi O, Lawal A, Brieger WR, Bloom G and Peters DH (2007) Malaria Treatment and Policy in Three Regions in Nigeria: The role of Patent Medicine Vendors. Future Health Systems Working Paper I. www.futurehealthsystems.org

Onabanjo, O. D., and Nwokocha, E. (20I2). Dying along the Ladder of Stratification: A View of Rural-Urban Dichotomy in Malaria Treatment among Pregnant Women in Ondo State. Gender \& Behaviour, I0(2), 4792-48I2.

Onyeneho NG, Orji BC, Okeibunor JC, and Brieger WR (2013) Characteristics of Nigerian women taking Sulfadoxine/Pyrimethamine twice during pregnancy for the prevention of malaria. Int. J. Gynaecol. Obstet. 123 (2): I0I-104

Oshiname FO and Brieger WR (1992) Developing primary care training for patent medicine vendors in rural Nigeria. Social Science and Medicine 1992, 35: I477-I 484.

Roll Back Malaria Partnership: (2000) Abuja declaration and the plan of Action. Geneva: World Health Organization; 2000.

Salami KK and Brieger WR. (2006) Consumer Response and Satisfaction with Prepackaged Antimalarial Drugs for Children in Aba, Nigeria. International Quarterly of Community Health Education. 24 (3) 213-227.

Salami KK and Olugbayo AO (2013) Health-seeking Behavior of Migrant Beggars in Ibadan, Southwestern Nigeria. Health, Vol. 5 No. 4: 792804.

Troisi J (2004) "Ageing in Africa: Older persons as a resource" A paper presented at the International Conference on "Rapid Ageing and the changing role of the elderly in African households", Organized by the Union for African Population Studies UAPS/UEPA (Senegal), the HSRC in collaboration with the Department of Social Development (South Africa) 18-20 August, 2004, Pretoria, South Africa.

Unanka GO (2002) Family Support and Health Status of the Elderly in Imo State of Nigeria. Journal of Social Issues, Vol. 58, No. 4, 2002, pp. 68I-695.

UNICEF (2004). The state of Africa's children and youth: perspective from West and Central Africa. Dakar: UNICEF, 9-16.

World Health Organisation (2000) \$I to roll back malaria. Partnership I (8): 9.

WHO (2010) World Malaria Report: World Health Organization; Geneva 201 I.

World Health Organization (20II) World Malaria Report 20II Geneva: WHO: 20I I. http:// www.who.int/malaria/world_malaria_report_20III en/. Accessed $27^{\text {th }}$ May 2012 .

World Health Organization (2012) Regional Office for Europe: Centralized information system for infectious diseases (CISID). 20I2. Available at: http://data.euro.who.int/cisid. Accessed 27th May 2012.

WHO (2013) Definition of an older or elderly person. Health Statistics and health information systems. World Health Organisation. http:// www.who.int/healthinfo/survey/ageing/en/ index.html. Accessed, 8/8/20I3. 